\title{
EFFECT OF OXIDATIVE MODIFICATION OF ACTIVATED CARBON ON SURFACE CHEMISTRY, POROSITY AND TARTRAZINE ADSORPTION
}

\author{
Monica Mangla \\ Department of chemistry, P.G.G.C-11, Chandigarh, India \\ Meenakshi Goyal \\ Dr S.S.B University Institute of Chemical Engineering \& Technology, \\ Panjab University, Chandigarh, India \\ Ganga R Chaudhary, Madan L Sharma \\ Department of Chemistry and Centre of Advanced Studies in Chemistry, \\ Panjab University, Chandigarh, India
}

\begin{abstract}
The surface chemistry and pore structure of porous activated carbons determine their application. Activated carbons (ACs) were modified by oxidization and degassing. The effect of oxidation and degassing on the textural properties such as surface area, pore size, pore volume, and surface chemistry was thoroughly examined by using elemental analysis, Fourier transform spectroscopy, SEM analysis, surface acidity/basicity and pHZPC measurements. The micropore volume and surface area decreases with oxidation treatment and increases on degassing. The adsorption capacity of the oxidized samples for tartrazine dye is poor than the untreated activated carbons.
\end{abstract}

Key words: Oxidative modification, pore size, porous activated carbon, surface acidity, tartrazine

\section{INTRODUCTION}

Contamination due to release of large number of toxic chemicals into the environment is the major undesirable features. Many governments have established strict standards for clean air and water. So the development of improved methods for the controlled release of toxic contaminants and designing of new materials to remove a wide range of contaminants is necessary. Adsorption is extremely attractive for this purpose because of their ease of operation. Tartrazine is an azobenzene artificial yellow water soluble acidic dye. It is known to cause allergic reactions such as asthma and urticaria $(1,2)$. Neurobehavioral parameters of human beings have also been affected by tartrazine (3). It may cause thyroid tumors and chromosomal damage.
Several adsorbents such as bottom ash and De-oiled soya (4) chitosan-coated bentonite (CCB) beads (5) polystyrene anion exchange resins (6) and activated carbons prepared from different sources (7-10) have been used for the removal of tartrazine from aqueous solution. Adsorption of tartrazine by activated carbons prepared from different sources has been intensively investigated, but relatively less work is reported related to modified carbons. In this research paper, we examine how the pore size and surface chemistry through oxidation and degassing affects the $\mathrm{AC}$ in the adsorption of tartrazine.

\section{EXPERIMENTAL}

Preparation of modified activated carbons

Oxidation with nitric acid was carried out by treatment of commercial activated carbon with nitric acid solution. About $400 \mathrm{ml}$ of $50 \%$ nitric acid was added to $10 \mathrm{~g} \mathrm{AC}$ and the mixture was placed on a water bath maintained at about $80^{\circ} \mathrm{C}$. When about $10 \mathrm{ml}$ of the acid is left, the contents are diluted with distilled water and then filtered. The sample is then washed exhaustively with hot distilled water and dried at $120^{\circ} \mathrm{C}$.

Oxidation with hydrogen peroxide included the addition of about $10 \mathrm{~g}$ of carbon sample in a stoppered reagent bottle containing $700 \mathrm{ml}$ of a $3 \mathrm{~N}$ solution of hydrogen peroxide. The mixture was placed for about $48 \mathrm{hrs}$ with intermittent shaking. The treated sample was then filtered off, washed with distilled water and dried at $110^{\circ} \mathrm{C}$. 
Degassing of oxidized activated carbons has been carried out by the elimination of carbon oxygen surface groups formed during oxidation at $950^{\circ} \mathrm{C}$. Temperature controlled tube furnace was used for degassing. In this quartz tube furnace, $5 \mathrm{~g}$ of a carbon sample was placed in a thin layer of about 5 inches in length. The tube furnace is then connected to a Hyvac.Cenco vacuum pump capable of giving vacuum to an order of $3 \times 10^{-3} \mathrm{~mm}$ of $\mathrm{Hg}$. Appropriate voltage is then applied to set its temperature at desired level. To avoid reformation of the carbon-oxygen complexes, degassed sample is allowed to cool in vacuum. The cooled sample is then transferred to stoppered bottles flushed with nitrogen.

\section{BET Surface Area and Pore Size distribution}

Nitrogen adsorption-desorption isotherms were measured at 77 K by using a Quantachrome Instuments Nova 2200e Surface area and Pore size analyzer. From these isotherms BET surface area, total pore volume and average pore radius of a particular activated carbon sample is determined. The activated carbon samples were degassed for $6 \mathrm{~h}$ at $320^{\circ} \mathrm{C}$ before the analysis. Approximately $0.10 \mathrm{~g}$ of sample is used for this analysis. The surface area is determined using the BET equation, while the total pore volume is directly calculated from the volume of nitrogen held at the highest relative vapour pressure $(\mathrm{p} / \mathrm{po}=0.99)$. Pore size radii are determined by Dubinin-Astakov equation. All calculations are done using NovaWin software provided with the analyzer.

\section{Elemental Analysis}

Elemental analysis was performed using a Flash 2000 CHNSO Organic Elemental Analyzer. Determination of carbon, hydrogen, nitrogen and sulfur is carried out in $\mathrm{CO}_{2}, \mathrm{H}_{2} \mathrm{O}, \mathrm{N}_{2}$ and $\mathrm{SO}_{2}$ forms, respectively. The analyzer uses a combustion process to break down substances into simple compounds which are then quantified. The sample of approx. $1 \mathrm{mg} \mathrm{AC}$ is prepared in a tin paper (CHNS analyses) or silver (O analysis). The combustion of the sample at $1800^{\circ} \mathrm{C}$ (pyrolysis at $1070^{\circ} \mathrm{C}$ in the case of $\mathrm{O}$ analysis) release gases which undergo a cycle of treatment (oxidation and reduction) in a tube reactor. The eluted gases are conveyed to the thermal conductivity detector TCD that generates electrical signals (processed by the Eager 300 software) for the Nitrogen, Carbon, Hydrogen, and Sulfur percentages contained in the sample.

\section{Scanning electron micrograph (SEM)}

The Scanning Electron Microscopy is a technique of electronic microscopy based on the electrons-material interactions. The interaction of the electrons provided by SEM with the material initiates a number of reactions inside the sample which results in the generation of signals which can give information about the sample. The surface morphology and pore structure of ACs were analyzed by Hitachi S-4300 scanning electron microscope (SEM) at accelerating voltages of 10-20 k. Prior to analysis, samples were dried and then coated with ultrathin coating of gold with Fine coat ion sputter (JFC 6100).

\section{Fourier Transform Infrared Spectrometer (FTIR) Analysis}

Perkin Elmer-Spectrum RX-1 Fourier Transform Infrared Spectrometer was used to measure the infrared spectrum of the ACs and to identify their chemical functionality. The ACs were dried at $150^{\circ} \mathrm{C}$ prior to IR evaluation. The spectra were recorded as $\mathrm{KBr}$ pellets in the $4000-500 \mathrm{~cm}^{-1}$ spectral range. The $\mathrm{KBr}$ pellets are prepared by mixing and grinding the activated carbon with $\mathrm{KBr}$ (mass ration 1:100) in a pestle mortar and then pressing the resulting mixture under pressure of $8 \times 10^{4} \mathrm{~N}$ in hydraulic press.

\section{Base neutralization capacity (Surface acidity and basicity)}

$1 \mathrm{~g}$ each of a carbon sample was placed in contact with $100 \mathrm{ml}$ of $0.1 \mathrm{~N}$ sodium hydroxide solutions in a stoppered bottle. The contents were placed on a water bath at $80^{\circ} \mathrm{C}$ for $6 \mathrm{~h}$. The mixture was then cooled and an aliquot volume of supernatant liquid was titrated against standard hydrochloric acid solution. The amount of alkali neutralized gives the surface acidity of the carbon sample. Basicity of carbon samples was determined by similar procedure where carbon samples were placed in contact with $0.1 \mathrm{~N} \mathrm{HCl}$ solution and titrated against standard $\mathrm{NaOH}$ solution.

\section{Zero point charge pH (pHzPc)}

The point of zero charge of as received and oxidized ACs were determined by the solid addition method (11). $20 \mathrm{ml}$ of $0.1 \mathrm{M} \mathrm{KNO}_{3}$ solution was taken in series of test tubes and $\mathrm{pH}_{0}$ values of the solution were roughly adjusted from 2 to 12 by

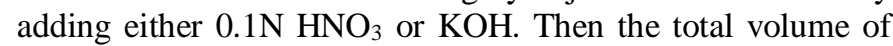
each solution was made exactly to $30 \mathrm{ml}$ by adding the $\mathrm{KNO}_{3}$ solution of the same strength. The $\mathrm{pH}_{0}$ of the solutions were then accurately noted and then One gram of carbon sample was added to test tube. The suspensions were allowed to equilibrate for $24 \mathrm{~h}$ with intermittent manual shaking. The $\mathrm{pH}$ values of the supernatant liquid were noted. The difference between the initial and final $\mathrm{pH}\left(\mathrm{pH}_{\mathrm{f}}\right)$ values $\left(\triangle \mathrm{pH}=\mathrm{pH}_{0}-\mathrm{pH}_{\mathrm{f}}\right)$ was plotted against the $\mathrm{pH}_{0}$. The point of intersection of the resulting curve at which $\Delta \mathrm{pH}=0$ gave the value of $\mathrm{pH}_{\mathrm{ZPC}}$ of carbon.

\section{Adsorption study}

The adsorption capacity of as-received and modified activated carbons was compared. $0.1 \mathrm{~g}$ of adsorbent and a $20.0 \mathrm{~mL}$ of tartrazine dye solution $\left(100-1000 \mathrm{mg} \mathrm{L}^{-1}\right)$ were placed in various $50.0 \mathrm{~mL}$ test tubes. The mixtures were agitated 




intermittently for $270 \mathrm{~min}$ at room temperature. UV/visible spectrophotometer was used to quantify the residual of dye in solution after adsorption at a maximum wavelength of 426.8 nm.

The amount of dye adsorbed at equilibrium $\mathrm{q}_{\mathrm{e}}(\mathrm{mg} / \mathrm{g})$ was calculated from the following equation:

$q_{e}=\frac{\left(C_{o}-C_{e}\right) V}{W}$

Where $\mathrm{C}_{0}$ and $\mathrm{C}_{\mathrm{e}}(\mathrm{mg} / \mathrm{L})$ are the liquid phase concentrations of dye at initial and equilibrium, respectively, $\mathrm{V}(\mathrm{L})$ the volume of the solution, and $\mathrm{W}(\mathrm{g})$ is the mass of adsorbent used.

\section{RESULTS AND DISCUSSION}

\section{Effect of oxidation on the Pore Structure of ACs}

Our work shows a correlation between the oxidation, degassing, pore volume, and surface area. BET surface area data is shown for the treated and untreated ACs in Table 1. Aqueous phase oxidation lowered ACs surface area while degassing caused an increase in surface area. In addition, we observe that the average micropore size changed very little from the original value while the pore volume decreases with increasing oxidation. Similar results have been reported by Stavropoulos et al.(12).

Table.1. Pore size, surface area and pore volume of asreceived and modified activated carbons

\begin{tabular}{|c|c|c|c|}
\hline Samples & $\begin{array}{c}\text { BET } \\
\text { surface } \\
\text { area } \\
\left(\mathrm{m}^{2} / \mathrm{g}\right) \\
\end{array}$ & $\begin{array}{l}\text { Average } \\
\text { pore } \\
\text { radius } \\
\left(\mathbf{A}^{\circ}\right)\end{array}$ & $\begin{array}{l}\text { Micropore } \\
\text { volume } \\
\left(\mathrm{cm}^{3} / \mathrm{g}\right)\end{array}$ \\
\hline As-received AC & 1607.43 & 10.7 & 0.850 \\
\hline $\begin{array}{l}\text { Oxidized with } \\
\mathrm{HNO}_{3}\end{array}$ & 712.71 & 10.8 & 0.381 \\
\hline $\begin{array}{c}\text { Oxidized with } \\
\mathrm{HNO}_{3}+ \\
\text { degassed at } \\
950^{\circ} \mathrm{C}\end{array}$ & 883.68 & 10.6 & 0.470 \\
\hline
\end{tabular}

SEM observations of AC Fig. 1a revealed its porous texture. Fig. 1b shows the scanning electron micrograph of AC oxidized with nitric acid. The figure shows evidence that $\mathrm{AC}$ structure changed after oxidation.
Fig.1. Scanning electron micrographs of AC before (a) and after (b) Oxidation with nitric acid

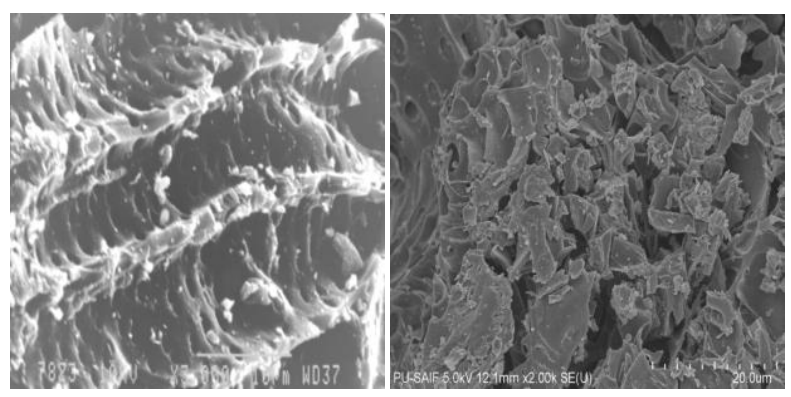

\section{Effect of Oxidation on Surface Chemistry}

FTIR was used for qualitatively analysis of the chemical functionality of untreated and treated ACs. Spectra are shown in Fig.2. Spectra show the differences in infrared absorption of as-received $\mathrm{AC}$, oxidized with concentrated nitric acid and degassed at $950^{\circ} \mathrm{C}$. The FT-IR spectra of as-received AC shows peak at $1564 \mathrm{~cm}^{-1}$ that represents the $\mathrm{C}=\mathrm{C}$ bond conjugated with another $\mathrm{C}=\mathrm{C}$ or a $\mathrm{C}=\mathrm{O}$ bond. Low intensity of bands for as-received carbon indicates the presence of fewer groups. However new and intense peaks appeared in the spectrum of oxidized sample. The band at $1713 \mathrm{~cm}^{-1}$ represents $\mathrm{C}=\mathrm{O}$ stretching vibration of carboxylic acids, 1574 $\mathrm{cm}^{-1}$ represent the stretching of aromatic rings. Peak at 1384 $\mathrm{cm}^{-1}$ correspond to $\mathrm{C}-\mathrm{O}$ stretching. On degassed sample intensity of these bands decreases due to removal of carbonoxygen groups.

Fig.2. FTIR spectra of (a) As-received AC (b) oxidized with nitric acid and (c) $950^{\circ}$-degassed samples of carbon

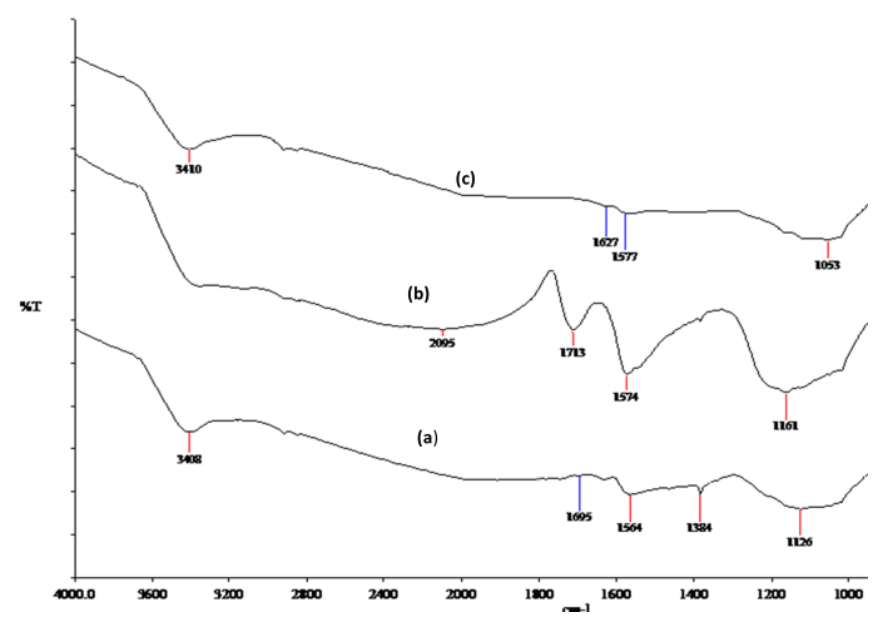

Composition and acidity/basicity of different as-received and modified activated carbon samples are presented in Table.2. The proportion of each element, specially the oxygen content 
gives more precise idea about the surface functional groups of AC. Oxidation results the product with low carbon and hydrogen content and increase in oxygen content. There is large increase in percentage of oxygen content in carbon oxidized with nitric acid as compare to carbon oxidized with hydrogen peroxide. Nitrogen and sulfur contents were not reported in Table 2 since the amount of these elements was not significant $(<1 \%)$.Acidity and basicity values confirmed the amphoteric behavior of these samples, in general more basic samples are the less acidic ones. It is seen from the table, acidity of carbon sample increases on oxidation and ACG-100 oxidized with nitric acid have the highest acidity and lowest basicity implies the presence of large amount of oxygen containing surface groups on oxidized samples. These results also agree with composition of samples.

TABLE.2. CHEMICAL COMPOSITION AND SURFACE ACIDITY/BASICITY OF AS RECEIVED AND OXIDIZED CARBON SAMPLES

\begin{tabular}{|c|c|c|c|c|c|}
\hline $\begin{array}{c}\text { Carbon } \\
\text { Sample }\end{array}$ & $\begin{array}{c}\text { Surface } \\
\text { acidity, } \\
\text { meq/100 } \\
\mathbf{g}\end{array}$ & $\begin{array}{c}\text { Surface } \\
\text { basicity, } \\
\text { meq/100 } \\
\mathbf{g}\end{array}$ & $\mathbf{\%} \mathbf{C}$ & $\mathbf{\% H}$ & $\mathbf{\% O}$ \\
\hline $\begin{array}{c}\text { As- } \\
\text { received } \\
\text { AC }\end{array}$ & 40 & 167 & 57.73 & 3.73 & 18.03 \\
\hline $\begin{array}{c}\text { Oxidized } \\
\text { with } \mathrm{H}_{2} \mathrm{O}_{2}\end{array}$ & 250 & 23 & 57.21 & 1.82 & $\begin{array}{c}21.2 \\
4\end{array}$ \\
\hline $\begin{array}{c}\mathrm{Oxidized}_{\text {with }} \\
\mathrm{HNO}_{3}\end{array}$ & 837 & 20 & 54.92 & 2.63 & 28.84 \\
\hline
\end{tabular}

Fig. 3 shows the plot between $\Delta \mathrm{pH}$ and $\mathrm{pH}_{0}$ for as-received and oxidized ACG-100. The point of intersection of curves with abscissa gave the $\mathrm{pH}_{\mathrm{ZPC}}$. The point of zero charge for ACG-100 is found to be 9.7 and for oxidized ACG-100 to be 1.7. This wide variation in $\mathrm{pH}_{\mathrm{ZPC}}$ of as-received and oxidized activated carbons shows the difference in the surface functional groups. Shift in the value of $\mathrm{pHzpc}$ from 9.7 for ACG-100 to around 1.7 for oxidized ACG-100 confirm the increase in degree of acidity

Fig.3. Point of zero charge of as-received AC and AC oxidized with nitric acid



\section{Effect of ACFs Oxidation on Adsorption}

We studied adsorption of tartrazine dye onto as-received, oxidized and degassed ACs. Fig.4. shows the tartrazine adsorption isotherms for different oxidation treatment and degassed samples. The decrease in uptake of tartrazine is more in case of nitric acid oxidized carbon as compare to hydrogen peroxide treated sample and increase in uptake on degassing implied that acidic groups played a negative role in the adsorption of dye. The total available pore volume and surface area also lower for oxidized sample as compare to as-received sample. But for degassed sample there is again increase in pore volume.

Fig.4. Adsorption isotherms of tartrazine for as-received, oxidized and degassed ACs

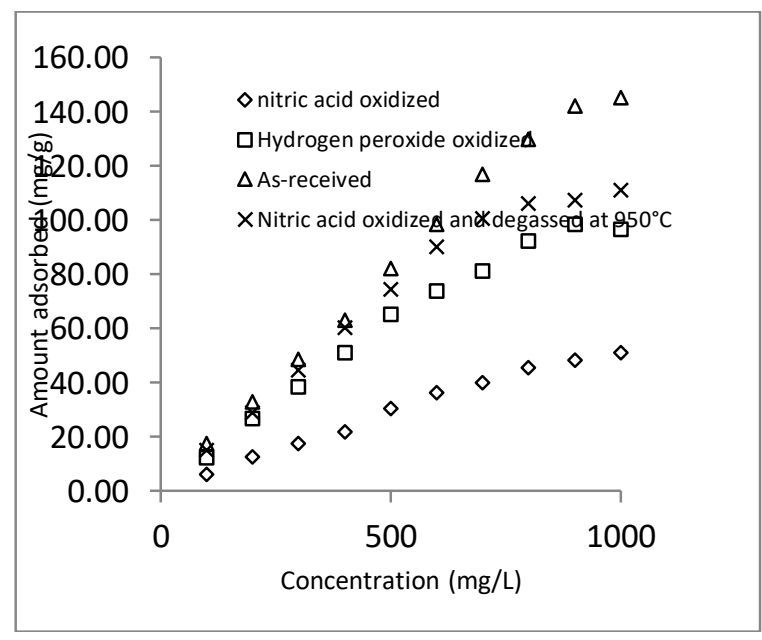




\section{CONCLUSION}

The effects of oxidation and degassing on pore structure and surface chemistry have been identified and can be used to tailor ACs for removal of specific contaminants. The decrease in adsorption performance upon oxidation can be attributed to an increase in acidic oxygen containing functional groups and decrease in micropore volume. These results may help in optimization of adsorbent and designing an adsorption equipment for the removal of tartrazine from aqueous solution.

\section{ACKNOWLEDGEMENT}

We are thankful to Dr R. C. Bansal for going through the manuscript and for their valuable suggestions.

\section{REFERENCES}

1) Williams, C.C. (1985). Clinical spectrum of adverse reactions to tatrazine, J. Asthma. 22(3) (pp. 139-43).

2) Moutinho, I.L.D.; Bertges, L.C. and Assis, R.V.C. (2007). Prolonged use of the food dye tartrazine (FD\&C yellow no 5) and its effects on the gastric mucosa of Wistar rats, Braz. J. Biol. 67(1), (pp. 1415).

3) Zhang, W.; Liua, T. ; Zhengb, X.; Huangb, W. and Wan, C. (2009). Surface- enhanced oxidation and detection of Sunset Yellow and Tartrazine using multi-walled carbon nanotubes film-modified electrode, Colloids surf., B: 74(1), (pp. 28-31).

4) Mittal, A.; Mittal, J. and Kurup, L. (2006). Adsorption isotherms, kinetics and column operations for the removal of hazardous dye, Tartrazine from aqueous solutions using waste materials--Bottom Ash and De-Oiled Soya, as adsorbents, J. Hazard. Mater. 136(3), (pp. 567-78).

5) Ngah, W.S.W.; Ariff, N.F.M. and Megat Hanafiah, M.A.K. (2010). Preparation,Characterization, and Environmental Application of Crosslinked ChitosanCoated Bentonite for Tartrazine Adsorption from Aqueous Solutions, Water, Air, Soil Pollut. 206(1-4), (pp. 225-236).

6) Wawrzkiewicz, M. and Hubicki, Z. (2009). Removal of tartrazine from aqueous solution by strongly basic polystyrene anion exchange resins, J. Hazard. Mater. 164(2-3), (pp. 502-9).

7) Al-Sarawy, A.; Rashed, I.G.; Hanna, M.A. and Wali, F.K.M. (2005). Removal of some 4-pyrazolone dyes from aqueous solutions by adsorption onto different types of carbon, Desalination. 186(1-3), (pp. 129153).

8) Zhang, J.; Zhang, P.; Zhang, S. and Zhou, Q. (2014). Comparative Study on the Adsorption of Tartrazine and Indigo Carmine onto Maize Cob Carbon, Sep.Sci. Technol. 49(6), (pp. 877-886).
9) Ozdemir, C.S. and Onal, Y. (2014). Error Anlaysis Studies of Dye Adsorption onto Activated Carbon from Aqueous Solutions, Part. Sci. Technol. 32, (pp. 20-27).

10) Gupta, V.K.; Jain, R.; Shrivastava, M. and Nayak, A. (2010). Equilibrium and Thermodynamic Studies on the Adsorption of the Dye Tartrazine onto Waste "Coconut Husks" Carbon and Activated Carbon, J. Chem. Eng. Data. 55 (11), (pp. 5083-5090).

11) Alzaydien, A.S. (2009). Adsorption of methylene blue from aqueous solution onto a low cost natural jodanian Tripoli, Am. J. Environ. Sci. 5(3), (pp. 197208).

12) Stavropoulos, G.G.; Samaras, P. and Sakellaropoulos, G.P. (2008). Effect of activated carbons modification on porosity, surface structure and phenol adsorption, J. Hazard. Mater. 151, (pp. 414-421). 